\title{
ENTREVISTA COM MARIA HELENA CAPELATO
}

\section{INTERVIEW WITH MARIA HELENA CAPELATO}

Rosangela Patriota Ramos ${ }^{1}$

Rodrigo Freitas Costa ${ }^{2}$

Thaís Leão Vieira ${ }^{3}$

Recebido em: 30 de novembro de 2020. Aprovado em: 18 de dezembro de 2020.

\section{https://doi.org/10.46401/ardh.2020.v12.12336}

A professora Maria Helena Capelato contribuiu com o Dossiê Cultura e Democracia: convergências, conflitos e interesses públicos, por meio de entrevista online preparada pelas professoras Rosangela Patriota e Thaís Leão Vieira e pelo professor Rodrigo de Freitas Costa. O dossiê que tem como um dos objetivos colocar em análise a cultura política brasileira nos últimos anos, nos remete a uma pluralidade de discussões que envolve diferentes áreas do conhecimento acadêmico. Quando olhamos especificamente para o campo historiográfico a percepção não é diferente. É possível empreender inúmeras análises sobre o tema, levando inclusive em conta os variados campos e áreas que compõe a História. Nesse ambiente, os trabalhos da historiadora Capelato se destacam especialmente pelas discussões sobre a articulação entre democracia, posicionamento ideológico, imprensa no Brasil e na América Latina. Além disso, a professora é reconhecida por sua militância em nome do conhecimento acadêmico sério e pela convicção de que a História é fundamental para influenciar interesses públicos e atuar no contínuo processo de formação democrática.

A carreira de Maria Helena se inicia com pesquisas voltadas para a imprensa brasileira no início do século XX, ganha dimensões mais consistentes com a preparação e finalização do mestrado, desenvolvido em parceria com Maria Lígia Prado, defendido em 1974 na USP, sob a orientação do Professor Carlos Guilherme Mota e publicado pela primeira vez em 1980 com o título "O Bravo Matu-

1 Bolsista Produtividade CNPq. Professora Assistente Doutora do Programa de Pós-Graduação em Educação, Artes e História da Cultura da Universidade Presbiteriana Mackenzie. Professora Titular aposentada da Universidade Federal de Uberlândia. Autora de Antonio Fagundes no palco da história: um ator; A crítica de um teatro crítico; Teatro brasileiro: ideias de uma história (em coautoria com J. Guinsburg), Vianinha - um dramaturgo no coração de seu tempo e História e Teatro: discussões para o tempo presente, entre outras publicações. É uma das editoras do periódico Fênix - revista de História e Estudos Culturais. E-mail: patriota. ramos@gmail.com

2 Professor Associado do Departamento de História da Universidade Federal do Triângulo Mineiro (Uberaba-MG), professor colaborador do Programa de Pós-Graduação em História da Universidade Federal de Uberlândia e membro da Rede de Pesquisa em História e Culturas no Mundo Contemporâneo. E-mail: rodrigo.costa@uftm.edu.br

3 Doutora em História pela Universidade Federal de Uberlândia (UFU). Professora do Departamento de História e do Programa de Pós-graduação em História da Universidade Federal de Mato Grosso (UFMT). E-mail: thaisleaovieira@gmail.com 


\section{ENTREVISTA}

tino: Imprensa e Ideologia". O centro dessa pesquisa é a análise da perspectiva política e ideológica liberal do Jornal O Estado de São Paulo, o que trouxe inúmeras contribuições ao campo historiográfico, tais como: a análise das singularidades do liberalismo no Brasil que conviveu com a escravidão durantes anos, a percepção de que para parte das elites de São Paulo o liberalismo era interpretado como forma de justificar o direito à propriedade e também a possibilidade do uso de jornais como fonte de pesquisa pelo historiador, algo inovador para a época.

Todo esse início promissor de pesquisa foi adensado ao longo do tempo, em especial quando a historiadora ampliou a temporalidade de suas pesquisas e defendeu também na USP, em 1986, a tese de doutorado "Os intérpretes das Luzes: liberalismo e imprensa paulista (1920-1945)". Nessa época, Capelato já era professora de História da América na Universidade de São Paulo e, novamente em conjunto com Maria Ligia Prado, rediscutia e repropunha a pesquisa e o ensino sobre História da América no Brasil. É por esse caminho que a historiadora mergulhou no campo da história comparada e desenvolveu pesquisas na Argentina que levaram à publicação do livro "Multidões em Cena: propaganda e política no Varguismo e no Peronismo", em 1998. Nesse contexto, vieram inúmeros artigos, capítulos e livros que formaram - e ainda formam - uma geração de historiadores no Brasil.

Por esse rápido itinerário, é possível perceber que a força da pesquisa de Capelato se expressa não só pelo tema, mas também pela capacidade reflexiva que é capaz de suscitar. A imprensa é elemento fundamental para a sustentação do Estado Democrático de Direito em qualquer parte do mundo, no entanto, é importante considerar que, além dessa ampla ideia, existem singularidades históricas e regionais capazes de interferir nas nuances democráticas de determinado povo. No caso do Brasil, isso é visível e os estudos de Capelato nos permite perceber com acuidade parte de nossa democracia e suas instituições. Esse é o elemento que torna central a entrevista da historiadora em um dossiê que tem como tema as articulações entre Cultura e Democracia. Como pensar a democracia brasileira frequentemente sob ataque? Capelato nos ajuda a redimensionar a pergunta colocando o acento interpretativo sob uma perspectiva temporal que nos leva a entender que as ofensivas antidemocráticas, por mais que sejam frequentes hoje, nunca deixaram de existir em um país que tem dificuldade para compreender os ideais liberais desde o início do século passado. É por essas e outras que o retorno constante ao que a historiadora escreveu é fundamental para entender nossa identidade política na atualidade. Hoje muito se fala em democracia, direito à expressão livre, valorização da divulgação de ideias e liberalismo político por meio de nossa "grande imprensa", porém pelas letras de Capelato é possível entender como tal posicionamento ideológico é elástico entre nós e, por isso, capaz de ser redimensionado conforme os interesses dominantes.

Devido à importância de suas reflexões, Maria Helena Capelato tornou-se uma voz importante nos meios de divulgação do conhecimento histórico e nas associações que defendem a pesquisa histórica e o trabalho dos historiadores. Ela é uma das fundadoras, em 1993, da Associação Nacional de Pesquisadores e Professores de História das Américas (ANPHLAC) e membro atuante da Associação Nacional de História (ANPUH), da qual foi presidente no biênio 2015-2017, momento de longas discussões públicas sobre a democracia no Brasil. Além disso, atuou no comitê de área da Capes e se fez presente de norte a sul do país como profunda apoiadora da ampliação da pós-graduação em 
História no Brasil. Enfim, mais que uma pesquisadora de primeira linha, ela é militante convicta da importância da reflexão histórica para a democracia de nosso país.

$\mathrm{Na}$ conversa a seguir, os entrevistadores focaram suas questões no tempo presente, particularidade temporal que a pesquisadora domina bem e os leitores perceberão que nenhum tema em voga na atualidade se desvincula de reflexões mais pormenorizadas sobre o passado. Em outros termos, os problemas que enfrentamos agora são fruto de uma longa história política calcada em preconceitos, autoritarismos e arbitrariedades de todas as espécies. Nesse caso, o olhar de uma pesquisadora experiente e com forte vinculação com a divulgação do conhecimento acadêmico nos ajuda a compreender que mais que uma luta frequente em favor da pluralidade, da liberdade de expressão e da força criativa, precisamos ter também pleno conhecimento de que os erros do passado só desaparecem de fato quando os acertos do presente estão calcados na reflexão. Por isso, Maria Helena Capelato é uma excelente companheira de análise e suas palavras expressas na entrevista funcionam como um estímulo para voltarmos aos seus textos e livros em busca de respostas para as dificuldades do nosso presente. Esperamos que as palavras da historiadora estimulem nos leitores as melhores características da entrevistada: o pensamento lúcido e crítico.

\section{Entrevista}

Entrevistadores: Uma das muitas dimensões envolvidas na vida docente da senhora são as pesquisas sobre populismo e vida política latino-americana, marcadas pelas modalidades de organização de poder e novas formas de controle social. Os fenômenos analisados estabelecem uma relação entre o caráter autoritário e a democracia nessas condições, envolvidos pelo uso da imprensa como fonte de pesquisa ou como objeto de estudo. Ao longo dessa carreira fecunda, a proximidade com a professora Maria Ligia Coelho Prado traz uma parceria valiosa, em especial no campo de estudos de história da América. Dito isso, a senhora poderia discorrer sobre essa trajetória acadêmica, a persistência do tema da imprensa e a extensão dessa parceria.

Maria Helena Capelato: Prefiro iniciar a resposta a partir da minha antiga relação acadêmica com Maria Ligia Coelho Prado, grande amiga e parceira desde os tempos da graduação no Departamento de História. Nossa primeira colaboração ocorreu no Mestrado, no início da década de 1970, e foi uma experiência inédita: o tema da imprensa, sugerido por nosso orientador, Carlos Guilherme Mota, não fazia parte do repertório, nem como fonte, nem como objeto da história. Além disso, a pesquisa foi realizada em conjunto, especificamente sobre o Jornal O Estado de S. Paulo. Com foco nos editoriais, analisamos a ideologia liberal que norteava o ideário do periódico.

Logo após a defesa do Mestrado, fui para a França onde, ao longo de cinco anos, realizei duas Pós-Graduações: uma, no Institut des Hautes Études de I'Amérique Latine (Sorbonne) e outra, na École des Hautes Études en Sciences Sociales. Quando voltei para o Brasil, realizei meu Doutorado, também sobre a imprensa. Nesta pesquisa, analisei os principais jornais da grande imprensa paulista, no período entre 1920-1945. 
As duas pesquisas foram publicadas em livros. O primeiro, em parceria com Maria Ligia, com o título O Bravo Matutino. Imprensa e ideologia: o jornal O Estado de S. Paulo, 1980. E a segunda, de minha autoria, com o título "Os Arautos do Liberalismo. Imprensa Paulista, 1920-1945".

O meu reencontro com Maria Ligia, do ponto de vista acadêmico, ocorreu quando ingressei como Professora de História da América, no Departamento de História da USP. Neste momento, importante destacar que, graças ao seu intenso trabalho, a disciplina História da América havia passado por uma grande transformação. Seguimos, desde então, trabalhando juntas, formando mestres e doutores nesta área.

Entrevistadores: A carreira da senhora na área de História é extensa. Já atuou como professora, orientadora e pesquisadora de reconhecimento nacional e internacional; atuou também, de maneira efetiva, no CNPq, na CAPES, na ANPUH e em outras instituições; além de ter presidido a ANPUH/Nacional, de 2015 a 2017 - momento político conturbado cujo ápice foi o processo de impeachment da presidente Dilma Rousseff. À época, o campo do debate histórico se viu repleto de discussões. Os assuntos iam do projeto "Escola sem Partido" às chamadas disputas de narrativas em torno do que acontecia no Congresso Nacional, para ficar em dois exemplos mais emblemáticos. Assim, tendo em vista a valorização do binômio CULTURA-DEMOCRACIA, como a senhora avalia, em relação aos últimos anos, o papel e o espaço da história na condição de área de conhecimento e da ANPUH como associação que congrega os profissionais brasileiros dessa área?

Maria Helena Capelato: Exerci os cargos, tanto na CAPES, como CNPq e ANPUH, porque o meu nome foi indicado pela comunidade de historiadores, e procurei exercê-los da melhor maneira possível. Quando assumi a Presidência da ANPUH nacional, em parceria com Lucília Neves de Almeida Delgado, amiga e companheira de todos os momentos, tivemos que enfrentar muitos obstáculos. Com apoio da comunidade de historiadores, realizamos muitos eventos com o intuito de nos manifestarmos contra "Escola sem Partido" e contra a proposta da Base Nacional Curricular, que diluía o ensino de História no conjunto de outras disciplinas. Também passamos a frequentar o Congresso Nacional com objetivo de que fosse aprovado o ofício do historiador - esta luta teve continuidade até este ano, quando, finalmente, a lei foi sancionada.

No que se refere à política nacional, a ANPUH se manifestou contra o impeachment da Presidente Dilma Rousseff.

Entrevistadores: A senhora se formou como historiadora durante a ditadura militar e se tornou professora na USP no ambiente da redemocratização. Que peso a ditadura teve no processo de formação da historiadora Maria Helena Capelato? Que responsabilidade o processo de abertura política trouxe para a pesquisadora que formaria novos profissionais da área? 
Maria Helena Capelato: Frequentei os cursos de graduação (1968-1971) e Mestrado (19721974), durante os "anos de chumbo". Nesse período, os órgãos de repressão estavam presentes na Universidade. A vigilância em relação aos cursos das humanidades era severa. Destaco que, nos anos finais da minha graduação, o Chefe do Departamento, Prof. Manuel Nunes Dias, o qual tinha afinidades com representantes da ditadura, exercia forte vigilância política junto a professores e alunos. Foi nesse contexto que ocorreu a cassação da Profa. Emília Viotti da Costa, entre outros professores de diferentes unidades de ensino.

Durante esse período, para colaborar com os amigos que haviam optado pela luta armada e viviam na clandestinidade, eu atuava como uma espécie de elo de ligação entre diferentes organizações clandestinas. E quando estava para a França, recebia com frequência, dos exilados que tinham conseguido sair do país, notícias das contínuas perseguições a alunos e professores.

Em suma, viver os "anos de chumbo" foi uma experiência muito difícil.

Entrevistadores: Para que a democracia no Estado moderno se sustente, a formação educacional tem papel imprescindível. Afinal, a escola, dentre outros pontos, prepara para a vida em coletividade, o que pressupõe tolerância e disponibilidade a debates públicos diferentes. Tendo em vista o processo de formação que permeia sua carreira, como a senhora enxerga o ensino de história e o processo de formação de professores/pesquisadores no Brasil atual? E que papel têm esses dois processos na construção constante da democracia brasileira? Ainda pensando sobre a formação dos professores de História nos últimos anos, como a senhora avalia programas importantes criados pela Capes, como o Programa Institucional de Bolsas de Iniciação à Docência (PIBID) e o Mestrado Profissional em Ensino de História (ProfHistória)?

Maria Helena Capelato: Considero extremamente importante os programas de formação de professores de história. Tanto o PIBID como o ProfHistória foram iniciativas louváveis da CAPES. Participei, nos primeiros anos de implantação, do ProfHistória e considerei esta experiência muito oportuna porque permitia a formação de professores de regiões distantes, com difícil acesso ao Mestrado na área de educação.

Entrevistadores: Recentemente, o CNPq lançou regras de financiamento da pesquisa acadêmica que priorizam algumas áreas do conhecimento em detrimento de outras: a área de História não é tida como prioritária. Ao mesmo tempo, há uma exigência frequente por parte das agências de fomento à pesquisa pela internacionalização da área de História. Como a senhora vê esse novo regramento de financiamento público e as exigências dos órgãos de fomento? Tudo isso pode ter relação com a constante necessidade de construir espaços e debates democráticos brasileiros?

Maria Helena Capelato: Na verdade, tanto o CNPq como a CAPES sempre priorizaram as áreas científicas em diferentes modalidades, em detrimento das áreas das "humanidades" - consideradas "saberes" de menor importância para o "progresso" do país. Ainda assim, se compararmos com os tempos atuais, as oportunidades eram várias. Hoje, o que vemos são os financiamentos da CAPES, CNPq e agências estaduais, como FAPESP, se tornarem cada vez mais escassos. Esta situação é 
lamentável. A ausência ou escassez de recursos para uma formação aprimorada no exterior, dificulta não apenas a pesquisa, mas também o contato com/entre pesquisadores estrangeiros que, em muitos casos, resulta em intercâmbios profícuos, os que possibilitam a realização de projetos em parcerias com colegas de outros países.

Entrevistadores: Ainda no diapasão da pergunta anterior, é fácil perceber que nos últimos anos o número de pesquisas na área de história no Brasil teve ampliação significativa, em parte por causa do aumento do número de pós-graduações Brasil afora. Além disso, houve muitas renovações no campo dos estudos históricos. Como a senhora percebe a pesquisa acadêmica em história no Brasil hoje? É capaz de abarcar a amplitude de nossa cultura política?

Maria Helena Capelato: Com certeza. As pesquisas na área de história no Brasil se expandiram em função da ampliação do número de Cursos de Pós-Graduação, implantados em diversas regiões. E, neste caso, cabe lembrar que a CAPES foi responsável por essa ampliação de cursos, mas também, pelo intercâmbio entre historiadores de diferentes partes do país.

Entrevistadores: No que se refere à pesquisa acadêmica e sua contribuição para ampliar a nossa cultura política, como a senhora apresenta historicamente o papel da imprensa no processo de construção da esfera pública no Brasil, sobretudo neste momento?

Maria Helena Capelato: Acredito que o papel da imprensa na formação da opinião pública se ampliou, não só em função da imprensa escrita mas, sobretudo, pelos múltiplos canais de informação que foram se criando e diversificando ao longo das últimas décadas.

Nesse sentido, conceitos de publicidade e opinião pública, construídos por Jürgen Habermas e outros autores, já não dão mais conta das mudanças ocorridas na forma de comunicação. $\mathrm{E}$ cabe indagar em que medida esses conceitos se sustentam em tempos de uma comunicação digital, via internet e redes sociais. O termo "opinião pública", por exemplo, continua sendo usado por institutos de pesquisa, porém, do ponto de vista acadêmico, eu acredito que essa noção precisa ser redefinida, bem como o seu entendimento em relação à democracia.

Entrevistadores: $O$ princípio da publicidade, em oposição ao controle das ações públicas e das chamadas fake news, opõe-se à formação da opinião pública como substância da razão. Nesse caso, como a senhora vê a democracia e a opinião pública em tempos de comunicação digital, internet e redes sociais on-line?

Maria Helena Capelato: Como foi dito na resposta à questão anterior, em tempos de comunicação digital, internet e redes sociais, a compreensão dessas formas de comunicação exige novas abordagens.

Entrevistadores: Em 2018, a Constituição Federal completou trinta anos. Em 2020, completam-se trinta e cinco anos do fim da Ditadura Militar. Na mídia do país, muito se ouve, se vê e se lê acerca de debates sobre a consolidação, ou não, de nossa democracia. Mas, embora haja tais discussões nos meios de comunicação, neles pouco se percebe a voz dos historiadores. Como a senhora per- 
cebe esse processo em que os profissionais da história nem sempre são chamados para debates de escopo mais amplo?

Maria Helena Capelato: Muitos historiadores que pesquisam temas relacionados à América Latina se dedicam a analisar o conceito de ditadura, sobretudo, em relação às que ocorreram na região do Cone Sul, nas décadas de 1960-80. Observa-se que esse conceito tem sido muito explorado, porém a noção de democracia tem sido pouco debatida. Isso se deve, talvez, ao trauma causado por regimes ditatoriais, ocorridos num passado recente.

\section{Referências}

CAPELATO, Maria Helena Rolim; Prado, Maria Lígia Coelho. O bravo matutino: imprensa e ideologia no jornal "O Estado de S. Paulo". São Paulo: Editora Alfa-Omega, 1980.

CAPELATO, Maria Helena Rolim. Multidões em cena: propaganda e política no varguismo e no peronismo. São Paulo: Papirus/FAPESP, 1998.

CAPELATO, Maria Helena Rolim. Os Arautos do Liberalismo. Imprensa Paulista 1920-1945. São Paulo: Brasiliense, 1989.

CAPELATO, Maria Helena Rolim. Os Intérpretes das Luzes: Liberalismo e Imprensa Paulista (1920-1945). 1986. Tese (Doutorado em História Social) - Universidade de São Paulo, São Paulo, 1986. 